\title{
Crítica e cultura em marketing: repensando a disciplina
}

\author{
Critique and Culture in Marketing: Rethinking the Discipline
}

\author{
Alexandre Faria ${ }^{1}$
}

\begin{abstract}
Resumo
Este artigo descreve o processo de implementação de uma abordagem crítica em marketing, baseada no realismo crítico e desenvolvida na Inglaterra e no Brasil por um pesquisador brasileiro. Inspirada inicialmente por uma proposta especifica de crítica em marketing desenvolvida na Inglaterra no início dos anos 1990 - o chamado rethinking marketing -, a pesquisa incorporou a cultura à crítica quando, no Brasil, o pesquisador passou a argumentar que o conhecimento produzido no mundo anglo-saxão não se aplica no Brasil. Através de uma abordagem confessional, composta pela descrição de diálogos do pesquisador com informantes e de reflexões e práticas correspondentes, o artigo mostra como é difícil adotar uma postura crítica na área de marketing. 0 autor argumenta que no Brasil os pesquisadores devem, pela promoção de pesquisas interculturais, privilegiar o conhecimento de informantes menos disciplinados e desafiar o argumento cultural de que o conhecimento aqui produzido não se aplica ao mundo anglo-saxão. No final, o artigo mostra como essa abordagem crítica pode ajudar a dar maior relevância à pesquisa acadêmica.
\end{abstract}

Palavras-chave: crítica; marketing; realismo critico

\begin{abstract}
The article describes the implementation process of a critical approach in marketing, based on the ontology of critical realism, developed in England and Brazil by a Brazilian researcher. The investigation, inspired at the onset by a particular critical approach developed in England in the early 1990s - the so-called rethinking marketing -, brought culture into the critical approach when, in Brazil, the researcher began to use in particular ways the argument that knowledge produced in the Anglo-Saxon world does not apply in Brazil. Through a confessional approach, consisting of description of dialogues between researcher and informants and corresponding reflections and practices, the article shows how difficult it is to develop a critical approach in marketing. The author argues that researchers in Brazil should, through the promotion of intercultural research, give emphasis to the knowledge mobilised by less disciplined informants in Brazil and challenge the cultural argument that knowledge produced in Brazil does not apply in the Anglo-Saxon world. In the end the article shows how this critical approach could raise the relevance of academic research.
\end{abstract}

Keywords: critique; marketing; critical realism

\section{Introdução}

No início da década de 1990, acadêmicos de diferentes nacionalidades, vinculados não somente ao marketing, reuniram-se no Reino Unido e propuseram que essa disciplina deveria ser repensada por meio de uma abordagem crítica (BROWNLIE et al, 1994, 1999). Até o momento, os proponentes do chamado rethinking marketing tiveram um êxito modesto. Esse nível de desempenho é revelado pela baixa proporção - especialmente, no circuito EUA-Europa - de pesquisadores críticos em marketing diante do chamado mainstream acadêmico (BROWNLIE; SAREN, 1992).

\footnotetext{
' PhD. em Administração de Empresas pela University of Warwick. Professor da Escola Brasileira de Administração Pública e de Empresas da Fundação Getulio Vargas EBAPE/FGV. Endereço: Praia de Botafogo, 190 - sala 535 - Botafogo - Rio de Janeiro - Brasil - CEP: 22250-900. E-mail: afaria@fgv.br.

Artigo recebido em abril de 2006 e aceito para publicação em junho de 2006.
} 
Inspirada principalmente por influências críticas e pós-modernistas, a abordagem proposta pelo grupo do rethinking marketing objetiva a emancipação da área pela eliminação de obstáculos ideológicos e disciplinares que bloqueiam o desenvolvimento de conhecimento relevante para praticantes e para a sociedade (MORGAN, 1992; O'SHAUGHNESSY, 1997). Cabe lembrar que as mencionadas influências críticas e pós-modernistas foram trazidas para a academia de administração por pesquisadores da área de estudos organizacionais; particularmente, por aqueles que não faziam parte do contexto acadêmico dos EUA e cedo se desencantaram com a idéia de "ciência pura", com o modelo funcionalista dominante e com a idéia de que as organizações resolveriam todo e qualquer problema social e econômico (BURRELL, 1996; BURRELL; MORGAN, 1979; CLEGG; PALMER).

$\mathrm{Na}$ área de marketing, as instituições e os mecanismos dedicados à preservação do status quo vêm obtendo contínuo êxito ante os que tentam transformar ou repensar a disciplina. Os "controladores" da disciplina, em sua maioria dos EUA, não desejam que a área de marketing reproduza a rota de fragmentação e pluralismo seguida por outras áreas, como a de estudos organizacionais. No contexto da globalização, instituições e acadêmicos importantes dos EUA têm contribuído para unificar as agendas e os interesses de pesquisa em diversos países, incluindo o Brasil (GRINBERG; LUCE, 2000).

Em termos comparativos, podemos afirmar que a área de marketing no Brasil é bem mais subordinada aos EUA do que, por exemplo, a de estudos organizacionais. A grande maioria dos pesquisadores de marketing no Brasil não valoriza as críticas à hegemonia americana e a conseqüente supressão do pluralismo na área (O'SHAUGHNESSY, 1997) e da crítica. Esses pesquisadores tampouco valorizam a crítica de pesquisadores brasileiros à importação sistemática de conhecimento anglo-saxão em administração.

Baseada tanto na literatura internacional quanto na produção local no passado (RAMOS, 1981), a crítica ao conhecimento produzido no mundo anglo-saxão teve um boom no Brasil a partir de meados dos anos 1990 (CALDAS; WOOD JUNIOR, 1997; MOTTA; ALCADIPANI; BRESLER, 2001; MOTTA; CALDAS, 1997; RODRIGUES; CARRIERI, 2001). Diferentes autores, muitos deles da área de estudos organizacionais, passaram a argumentar que teoria e pesquisa no Brasil devem refletir a cultura nacional. De acordo com esse ponto de vista, teoria e conhecimento construídos no mundo anglo-saxão não fazem sentido no Brasil.

O desinteresse pela proposta do rethinking marketing no Brasil, a histórica distância entre a área de marketing e outras áreas do conhecimento (BAZERMAN, 2000; KNIGHTS; MORGAN, 1993) e a potencial argumentação calcada na questão cultural por parte de pesquisadores de marketing no Brasil (VIEIRA, 2003) constituem o foco deste artigo. Por meio de uma abordagem confessional (VAN MAANEN, 1996), o autor descreve e analisa episódios de uma pesquisa intercultural feita no Brasil e na Inglaterra, em que desenvolveu uma abordagem crítica específica, baseada no realismo crítico.

\section{0 rethinking marketing e a crítica em marketing}

Em simpósio realizado em julho de 1993 na Universidade de Warwick, no Reino Unido, acadêmicos do marketing e de outras áreas, de diferentes nacionalidades, defenderam a adoção de uma abordagem crítica nesta área. A abordagem crítica defendida pelos proponentes do rethinking marketing tinha como objetivo que se atribuísse relevância e status acadêmico (BROWNLIE et al, 1994, 1999) a essa importante área. Os organizadores do simpósio não defendiam o radicalismo, mas o reconhecimento de que a pesquisa acadêmica em marketing costuma excluir e silenciar vozes de importantes "outros" (DEETZ, 1996, p.194; HAMMERSLEY, 1995). Em busca dessa relevância, o principal objetivo da abordagem crítica do rethinking marketing era "liberar o potencial criativo que corria o risco de, de outra forma, continuar adormecido ou negado." (BROWNLIE et al, 1999, p.2)

Em resumo, os organizadores do simpósio não buscavam a mera mobilização da crítica pela crítica, mas sim o aproveitamento de possibilidades libertadoras a partir do reconhecimento das tensões existentes entre o pensamento dominante no marketing e as diferentes críticas dirigidas a esse pensamento. Essa abordagem desafia três grandes problemas enfrentados pela disciplina: 
- a crescente mercantilização do conhecimento acadêmico (BROWNLIE; SAREN, 1995);

- o caráter excessivamente "cientificista" imposto por acadêmicos e instituições dos EUA (GUMMESSON, 2001); e

- a falta de preocupação geral dos pesquisadores com questões de epistemologia, de metodologia e de ontologia (EASTON, 1995).

De acordo com a abordagem crítica proposta pelo rethinking marketing, os pesquisadores deveriam testar teorias e modelos correntes com criatividade ou gerar novas teorias, ao invés de meramente confirmar ou estender teorias existentes (O’DRISCOL; MURRAY, 1998; O’SHAUGHNESSY, 1997; WENSLEY, 1995).

O livro Rethinking marketing - tido como "a mais extensa coletânea de artigos críticos em marketing publicados recentemente" (MORGAN, 2003, p.112) - reproduz nos anos 1990, questionamentos que vinham sendo tratados pela área de estudos organizacionais, principalmente fora dos EUA, desde o final dos anos 1970. Isso ajuda a explicar, por exemplo, a participação ativa de Gibson Burrell no simpósio de 1993 e no livro, publicado em 1999 (BURREL, 1999). Ainda que não explicitado na época por seus proponentes, o rethinking marketing está relacionado a reações culturais recentes, observadas em países fora do eixo EUA-Europa por pesquisadores descontentes com o avanço da hegemonia americana no campo da administração, no contexto da globalização (ALVAREZ, 1996; IBARRA-COLADO, 1996; MOTTA; CALDAS, 1997).

A história mostra que a transformação de disciplinas ou paradigmas acadêmicos é muito difícil, não somente por questões cognitivas ou culturais, mas principalmente por questões políticas, ideológicas e materiais (ALVESSON, 1991; FULLER, 2000). Da mesma forma, defensores do rethinking marketing argumentam que influentes instituições baseadas nos EUA - especialmente, o American Marketing Science e o Marketing Science Institute (BROWNLIE; SAREN, 1995, 1997; WENSLEY, 2001) - continuam criando obstáculos, de forma direta ou indireta, à emergência dessa e de outras abordagens críticas em marketing.

É particularmente interessante ressaltar que instituições e mecanismos análogos não tiveram desempenho tão efetivo na área de estudos organizacionais, especialmente, fora dos EUA. Ao contrário da área de marketing, a área de estudos organizacionais tem a pluralidade e a fragmentação como características marcantes (CLEGG; HARDY; NORD, 1999). Essas características já estão tão presentes na área que grupos distintos de pesquisadores acabaram se formando. Há o grupo que defende a pluralidade, há aquele que defende a integração de paradigmas e há ainda o que vê a pluralidade como uma perigosa ilusão (ALVESSON; WILLMOTT, 1996; HASSARD, 1990; JACKSON; CARTER, 1991).

Cabe destacar que o grupo que defende a integração é o mais forte nos EUA (PFEFFER, 1993). Deve ser observado que é crescente a proporção de pesquisadores, conferências e publicações - principalmente fora dos EUA - que vêm desafiando propostas funcionalistas e "cientificistas" na área de estudos organizacionais (ALVAREZ, 1996; IBARRA-COLADO, 1996). Apesar de algumas controvérsias na literatura (DEETZ, 1996), é inegável que o trabalho pioneiro de Burrell e Morgan (1979) - um tipo de "rethinking organization studies" da época - contribuiu para que pesquisadores de diversos países viessem a desafiar as "certezas" ideológicas e institucionais que levaram à constituição da área no final do século XIX (REED, 1999).

A área de marketing - em grande parte devido ao tipo de hegemonia que se estabeleceu nos EUA - ignorou os movimentos em direção à pluralidade e à fragmentação iniciados na década de 1970, no Reino Unido, na área de estudos organizacionais. A área também conseguiu bloquear a ação de pesquisadores europeus em marketing que, nas décadas seguintes, defenderam a pluralidade e a incomensurabilidade de paradigmas (ARNDT, 1985; O'SHAUGHNESSY, 1997), paralelamente ao crescente domínio da pesquisa quantitativa e do positivismo estatístico na área (GUMMESSON, 2001). Ao longo desses processos, podemos destacar o papel exercido por influentes instituições, como a American Marketing Academy e o Marketing Science Institute, devendo ressaltar também o papel cumprido por alguns importantes acadêmicos americanos.

Shelby Hunt - um dos mais renomados acadêmicos da área e um dos principais convidados para o simpósio realizado em Warwick - cumpriu um papel importante ao rebaixar durante anos seguidos as propostas em defesa 
da pluralidade, classificando-as sistematicamente como niilistas, incoerentes, anárquicas e até mesmo rancorosas. Ele propõe que a pesquisa na área seja norteada pelo chamado "realismo científico" (HUNT, 1990, 1994), desconsiderando o fato de que essa proposta, fundamentada numa representação problemática de "ciência pura", vem sendo refutada há décadas pelo argumento de que fenômenos organizacionais podem ser compreendidos de muitas maneiras (MORGAN, 1997) ou de que "há múltiplas realidades organizacionais" (STABLEIN, 2001, p.67). ${ }^{2}$

Dado esse quadro de dificuldades, não causa surpresa que a abordagem crítica em marketing defendida pelo $r e$ thinking marketing no início dos anos 1990 não tenha encontrado muitos seguidores no eixo EUA-Europa, nem em outros contextos ou culturas. Além dos obstáculos conhecidos, tendo em vista os objetivos deste artigo, três obstáculos específicos merecem destaque. Primeiro, a carência de intercâmbios entre as áreas de marketing e de estudos organizacionais. Segundo, a histórica distância entre a área e seus praticantes (WENSLEY, 1995). Terceiro, a absoluta escassez de pesquisa intercultural que desafie o status quo da disciplina de marketing (FARLEY; LEHMANN, 2001; USUNIER, 1998).

O quadro corrente de obstáculos para o desenvolvimento da crítica em marketing - e, em particular, o tipo de abordagem crítica proposta pelo rethinking marketing - aponta para um cenário decepcionante: podemos prever, então, que uns poucos pesquisadores continuarão produzindo críticas radicais (MORGAN, 1992, 2003), as quais serão publicadas mas não lidas, enquanto a grande maioria continuará publicando, reproduzindo o mainstream.

A atmosfera resultante de ceticismo é preocupante (BROWN, 1997), principalmente, por causa da importância central da área de marketing no mundo contemporâneo, seja como ideologia ou conjunto de práticas, inclusive, para pesquisadores de outras áreas (BAZERMAN, 2000; GABRIEL, 2001; DU GAY; SALAMAN, 1992).

\section{Bases do realismo crítico}

Ainda que não muito aplicada nas ciências sociais ou na administração (ACKROYD; FLEETWOOD, 2000; HAMLIN, 2000) a ontologia do realismo crítico - que desafia o pressuposto de que a ciência é neutra ou imaculada - foi escolhida pelo autor deste artigo para o desenvolvimento de uma abordagem crítica em marketing alinhada aos principais pressupostos do rethinking marketing.

Roy Bhaskar, filósofo baseado no Reino Unido e um dos mais importantes proponentes do realismo crítico, argumenta que a realidade "lá fora" existe e que a mesma tem que ser descoberta, ao invés de ser imposta ou preferida pelo pesquisador. Esse argumento desafia as duas principais epistemologias científicas: o positivismo e o interpretivismo. Segundo o realismo crítico, o positivismo, largamente usado na área de marketing e pela academia dos EUA em geral, é problemático por reduzir o conhecimento à existência - a chamada "falácia ôntica". O interpretivismo, mais usado por alguns acadêmicos europeus e por pesquisadores da área de estudos organizacionais (principalmente, fora dos EUA), é tido como problemático por reduzir a existência ao conhecimento - a chamada "falácia epistêmica" (BHASKAR, 1978, p.37-38; 1989, p.22).

Em outras palavras, o realismo crítico desafia tanto o absolutismo ontológico quanto o relativismo ontológico. De acordo com realismo crítico, a realidade "lá fora" existe, ainda que não seja facilmente conhecida ou descoberta, e não "pertence" nem ao pesquisador, nem ao pesquisado. Isso significa, por exemplo, que o realismo cultural refutaria o argumento cultural de que o conhecimento e o entendimento da realidade no Brasil "pertencem" (exclusivamente) aos brasileiros. Em outras palavras, com base no pressuposto de que a realidade existe,

2 Isso ajuda a explicar por que Gibson Burrell foi convidado pelos editores do livro Rethinking marketing para criticar o capítulo escrito por Shelby Hunt. Esse capítulo não foi publicado porque Hunt não aceitou que seu texto fosse comentado por Burrell. Após longa disputa travada nos bastidores envolvendo os editores do livro, a editora e Hunt, o capítulo produzido por este não foi incluído no livro. No final das contas, o capítulo escrito por Burrell foi incluído. Tais disputas ajudam a explicar por que o livro foi publicado somente em 1999, seis anos após o simpósio realizado em Warwick e cinco após a publicação de número especial correspondente do European Journal of Marketing. 
a despeito do conhecimento que os agentes sociais têm sobre a realidade, realistas críticos desafiariam o argumento cultural de que conhecimento produzido em dado contexto ou dada cultura não se aplica a outro contexto ou a outra cultura.

Outro argumento importante do realismo crítico é o de que as práticas da pesquisa social não são neutras ou "naturais". A natureza daquilo que existe, em determinada investigação, está em grande parte relacionada ao modo como a pesquisa é realizada e ao que o pesquisador, de forma consciente ou não, concebe como "real" (ARCHER, 1995, p.16). Assim como os proponentes do rethinking marketing, realistas críticos refutariam a imposição de uma abordagem crítica radical em pesquisa porque ela iria corromperia o processo de descoberta da realidade pelo pesquisador.

Em oposição aos positivistas, os realistas críticos argumentam que pesquisa social tem que começar pelo ponto de vista dos agentes sociais. Ainda que esses agentes possam desconhecer ou conhecer de forma equivocada a realidade, as estruturas e os mecanismos causais na sociedade "não existem independentemente dos conceitos que agentes (sociais) têm sobre aquilo que estão fazendo." (BHASKAR, 1989, p.38). Entretanto, voltando ao primeiro argumento, realistas críticos ressaltam que aquilo que é conhecido ou verbalizado por atores sociais não pode ser tomado pelo pesquisador como equivalente à realidade, por duas razões:

- a realidade existe independentemente do conhecimento dos atores sociais, e

- o conhecimento dos atores sociais pode (e costuma estar) equivocado ou viesado (ACKROYD; FLEETWOOD, 2000; OUTHWAITE, 1983).

Segundo o realismo crítico o pesquisador deve não apenas descobrir a realidade e seus mecanismos e estruturas, mas também investigar as razões que levam atores sociais a desconhecer ou a verbalizar a realidade de forma equivocada. A descoberta da realidade como ela é e das estruturas e mecanismos que impedem que atores sociais a conheçam permitiria um certo tipo de emancipação dos mesmos.

O realismo crítico é particularmente compatível com a proposta do rethinking marketing por duas razões. Primeiro, porque essa ontologia desafia tanto o positivismo dominante na área quanto a imposição de uma abordagem crítica radical pelo pesquisador. Segundo, porque pode ajudar a revelar obstáculos que impedem que atores sociais conheçam a realidade como ela é. Apesar dessas virtudes, o realismo crítico ainda não encontrou muitos seguidores na área de marketing, além de alguns esforços isolados no Reino Unido (EASTON, 1995; KAVANAGH, 1994). A principal consequiência disso é que, assim como há sérias dificuldades para que princípios propostos por filósofos profissionais sejam aplicados por pesquisadores sociais (KINCHELOE; McLAREN, 1994; EASTERBY-SMITH; THORPE; LOWE, 1991), ainda se sabe pouco sobre como o pesquisador pratica o realismo crítico (FLEETWOOD; ACKROYD, 2004).

Realistas críticos argumentam que, durante o processo de descoberta, o pesquisador deve testar a plausibilidade de estruturas e mecanismos hipotéticos - muitos dos quais costumam "não estar disponíveis imediatamente para experiência." (HARRÉ, 1979, p.160). As hipóteses que forem avaliadas como mais plausíveis devem ser privilegiadas e tratadas como mais próximas da "verdade". Realistas críticos não fazem considerações de natureza mais prática, mas é possível prever que pesquisadores da área de marketing enfrentem mais dificuldades do que, por exemplo, os de estudos organizacionais para a operacionalização de tais princípios ontológicos e epistemológicos. Também é possível prever que, em pesquisa intercultural, pesquisadores de contextos menos desenvolvidos enfrentem mais dificuldades do que pesquisadores de contextos mais desenvolvidos, devido às assimetrias sociais e históricas no mundo acadêmico.

Pela descrição detalhada do processo de investigação numa pesquisa intercultural e crítica em marketing, o autor revela obstáculos disciplinares, acadêmicos e culturais que dificultam a operacionalização do realismo crítico. Mostra ainda como a aproximação com o argumento cultural defendido no Brasil, a partir de meados dos anos 1990, foi importante tanto para a superação de tais obstáculos quanto para a descoberta de que a abordagem cultural em si é um obstáculo para futuras pesquisas. 
A apresentação dos resultados segue uma abordagem confessional (VAN MAANEN, 1996), com o propósito de focar a atenção do leitor no processo de investigação - o qual costuma ser ignorado por pesquisadores, devido à baixa importância atribuída à reflexividade na área de administração (ALVESSON; SKÖLDBERG, 2000; JOHNSON; DUBERLEY, 2003). Os diálogos com gerentes e as situações correspondentes de reflexão-emação descritas neste artigo revelam como estruturas e mecanismos causais hipotéticos foram construídos, testados e representados pelo pesquisador.

\section{Método e descrição e análise dos resultados}

A investigação foi baseada no uso de estudos de casos (EISENHARDT, 1989; MILES; HUBERMAN, 1994; YIN, 1994) e seguiu as premissas básicas do realismo crítico. O principal objetivo era descobrir, em vez de impor teorias conhecidas e estabelecidas na área de marketing, as causas da cooperação entre firmas de redes industriais nos setores automotivo e eletrônico - no Brasil e na Inglaterra.

A literatura dominante em marketing prescreve que cooperação e redes interfirma são requisitos fundamentais para o desempenho empresarial, tendo em vista as pressões trazidas pela hipercompetição global e a reestruturação industrial (ACHROL, 1991). A proposta de crítica do rethinking marketing e o ceticismo de pesquisadores em estudos organizacionais no Reino Unido - especialmente na própria Universidade de Warwick (BRESNEN, 1996) - quanto a esse tipo de discurso ajudaram a promover uma primeira aproximação interdisciplinar nesta pesquisa. Com base num dos pressupostos do realismo crítico, gerentes foram tratados não como meros informantes-chave, mas como praticantes competentes (SCHÖN, 1983). Desde o início da investigação o pesquisador pressupôs que esses gerentes tinham elevada capacidade de 'fazer sentido' (tradução do autor para o termo 'sensemaking') e de refletir sobre suas práticas, ainda que fossem, potencialmente, desconhecedores de mecanismos e estruturas causais importantes que explicavam a cooperação interfirma de forma mais plausível.

A pesquisa de campo, realizada na Inglaterra e no Brasil, foi extensa e dispendiosa. Cinco casos, cada um abrangendo três ou mais firmas que faziam parte de determinada rede (denominada rede focal), foram investigados: o primeiro e o último casos na Inglaterra, os outros três no Brasil. Por limitação de espaço, neste artigo o autor descreve e analisa somente um dos casos investigados. Os nomes das empresas e dos informantes apresentados são fictícios, para preservar o caráter confidencial da investigação.

SPK é fornecedor direto das mais importantes montadoras do setor automotivo no Brasil e ALM é uma das maiores montadoras no país. O gerente de compras da SPK, J.T., foi tratado como informante-chave após ter sido indicado pelo gerente de vendas e de marketing, que a princípio fora escolhido como o informante-chave. A entrevista com J.T. desafiou alguns pressupostos que até então não tinham sido desafiados:

J.T.: sobre o que você quer realmente conversar? O problema é que há muitas coisas acontecendo ao mesmo tempo aqui na SPK [acompanhado de um sorriso sarcástico].

Eu: entendo... mas vamos nos concentrar nesse processo específico... [de cooperação entre SPK, ALM e MLC, esta última uma empresa fornecedora da SPK].

J.T.: para mim está tudo bem se você está realmente querendo conversar sobre como gerenciamos o fornecedor de pinos [MLC] naquela situação. Porém, eu tenho que dizer que estou fazendo isso porque você está me pedindo [sorrisos].

Eu: o que você quer dizer?[já um pouco irritado]

J.T.: o que já disse. No seu modelo (de investigação) as coisas estão muito simplificadas. As coisas acontecem aqui de forma muito mais complexa e rápida, entende?

Eu: entendo, mas o que estou tentando fazer é compreender esse processo específico... 
Esse difícil diálogo me fez lamentar a proposta de lidar com empresas das redes como se fossem "caixas pretas". Em outras palavras, esse diálogo me fez lamentar o fato de que a pesquisa era da área de marketing. Eu sabia que precisaria de muito mais tempo para lidar com empresas de forma mais complexa, como fazem pesquisadores da área de estudos organizacionais. Além da falta de tempo naquele estágio mais adiantado do doutoramento, outro problema é que o desenvolvimento de uma abordagem interdisciplinar desafiaria meus superiores da área de marketing e colocaria em risco a defesa da tese. No Reino Unido, muitos concordam com o argumento de que uma das principais características da área de marketing é a rejeição de qualidades acadêmicas como "abertura, tolerância e crítica [..]. que facilitam a inovação e novos modos de pensar." (BROWNLIE et al, 1994, p. 8)

Decidi, então, desenvolver outros argumentos "cientificamente" legítimos para não desafiar tanto a área de marketing. O primeiro argumento foi o de que a limitação de recursos e de tempo faz com que a pesquisa qualitativa tenha muitas incertezas e limitações (EASTON et al, 1995). O segundo argumento foi o de que em "qualquer processo de aprendizagem sempre haverá erros e inícios equivocados" (EASTERBY-SMITH; THORPE; LOWE, 1991, p.8). Esses dois argumentos metodológicos (ou epistemológicos) reduziam minha responsabilidade e atenuavam a frustração pela impossibilidade de escolher o caminho mais adequado à investigação.

O problema central era que, para responder à minha pergunta, J.T. sugeria que "coisas" que ocorriam dentro da SPK eram mais relevantes do que as que aconteciam no domínio interfirma. Esse tipo de argumentação não fora verificado até então nos casos investigados na Inglaterra. De forma consciente ou não, comecei a criar e a testar hipóteses para tentar provar que J.T. era um informante equivocado ou que desconhecia a realidade. Esse caminho não era tão difícil de seguir por duas razões:

- pesquisadores em marketing costumam desprezar as práticas e a capacidade da gerência (BROWNLIE, 1997; WENSLEY, 1995), e

- o realismo crítico pressupõe que o conhecimento dos atores sociais é sujeito a falhas (FLEETWOOD; ACKROYD, 2004).

Influenciado pelos pressupostos do rethinking marketing, continuei, por outro lado, fazendo descobertas interdisciplinares importantes. Pesquisadores na área de marketing costumam tomar gerentes e consumidores como meros "respondentes". Eles consideram que respondentes são "confiáveis, que vão cooperar, que são capazes de entender as perguntas e que têm excelente memória e opiniões estáveis." (O'SHAUGHNESSY, 1997, p.702)

$\mathrm{Na}$ área de estudos organizacionais (principalmente fora dos EUA), pesquisadores argumentam que as teorias que informantes usam costumam diferir, por diferentes razões, daquelas que eles evocam (ARGYRIS, 1976; STABLEIN, 2001; VAN MAANEN, 1979; WEICK, 1995;). Uma das razões é que informantes não podem falar tudo o que sabem por causa das pressões políticas dentro das grandes empresas (EASTERBY-SMITH; THORPE; LOWE, 1991). Outra razão é que informantes gostam de encerrar as entrevistas o mais rapidamente possível, “... para convencer o pesquisador de que ele está obtendo algo valioso, mas sem dizer coisa alguma que chegue à essência daquilo que é tratado...” (JONES, 1985, p.50)

Também "descobri” que a adoção de modelos formais em decisões é atípico em pesquisas na área de decisões organizacionais - o que é importante, tendo em vista a hegemonia de modelos formais na área de marketing por causa da complexidade atribuída às organizações e a seus membros (LANGLEY, 1989; PETTIGREW, 1973). Segundo o modelo da "lata de lixo", por exemplo, embora as organizações sejam vistas como meios para a solução de problemas, elas também fornecem conjuntos de procedimentos "pelos quais seus participantes chegam a uma interpretação do que estão fazendo e do que fizeram ainda durante o processo de tomar decisão" (COHEN; MARCH; OLSEN., 1972, p.2). Segundo esse modelo de análise de decisões, a organização é vista como "uma coleção de escolhas procurando problemas... soluções buscando questões para as quais poderiam ser as respostas e tomadores de decisão em busca de trabalho." (ibid, p.2) 
De certa maneira, o informante estava aproveitando a entrevista, para, em retrospectiva, relacionar uma determinada escolha a um determinado problema, segundo a lógica de causalidade prospectiva que eu, como pesquisador da área de marketing, estava impondo. O argumento de Weick $(1969$, p. 8) ilustra bem essa situação de descasamento.

It is as if persons acted so that they could eventually determine what it was that they had done. This sequence in which actions precede goals may well be a more accurate portrait of organizational functioning. The common assertion that goal consensus must occur prior to action obscures the fact that consensus is impossible unless there is something tangible around which it can occur. And this "something tangible" may well turn out to be actions already completed. Thus it is entirely possible that goals statements are retrospective rather than prospective.

Apesar da relevância desses argumentos para a pesquisa, eu sabia que eles não seriam bem recebidos pela área de marketing. É senso comum no mundo acadêmico que o pesquisador competente deve situar seu trabalho próximo ao que é tido como importante. Essa cobrança é maior em relação a pesquisadores de países menos desenvolvidos, especialmente, aos que buscam o doutoramento no mundo anglo-saxão. Aqueles que se afastam do mainstream, costumam ser, de uma forma ou de outra, "isolados dentro da academia." (EASTERBYSMITH; THORPE; LOWE, 1991, p.58). Cabe destacar aqui que o critical management studies (FOURNIER; GREY, 2000; VIEIRA; CALDAS, 2006) ainda não era uma realidade acadêmica no Reino Unido até meados dos anos 1990, particularmente, na área de marketing.

Outro obstáculo que eu enfrentava é que os estudos de caso não são bem aceitos na área de marketing, por não permitirem o necessário rigor científico e "objetividade" à pesquisa acadêmica (GUMMESSON, 2001). Por outro lado, descobri que pesquisadores em estudos organizacionais preferem estudos de casos porque estes proporcionam maior liberdade, tanto para os pesquisadores quanto para os pesquisados (CAMPBELL, 1975; STABLEIN, 2001; YIN, 1994).

Não foram animadoras as reações de pesquisadores da área de marketing com quem conversei a respeito. Decidi, então, tentar outra abordagem interdisciplinar, para poder usar as descobertas no Brasil, em vez de eliminálas. Aproveitando as críticas feitas por pesquisadores no Brasil à hegemonia anglo-saxônica, decidi abraçar essa abordagem "cultural" para embasar uma abordagem crítica naquela pesquisa. Para isso, parti do pressuposto de que a área de marketing está em estágio mais avançado no Reino Unido do que no Brasil, seja em termos de realidade dos mercados e das empresas quanto de conhecimento acadêmico. Através desse pressuposto, as "estranhas" descobertas no Brasil confirmariam as críticas feitas por locais. No final das contas, eu também defenderia o argumento de que modelos do mundo anglo-saxão não se aplicam ao Brasil e que pesquisadores locais deveriam produzir conhecimento em marketing adequado ao estágio de desenvolvimento do mercado, da economia, das empresas e dos gerentes locais.

Esse pressuposto subvertia uma das principais premissas do realismo crítico porque se baseava, no fundo, no argumento de que a realidade no Brasil "pertence" aos brasileiros. No final das contas, de alguma maneira, esse argumento era benéfico para mim. Primeiro, porque aumentava a probabilidade de aprovação de minha tese na Inglaterra. Segundo, porque após o doutoramento no Reino Unido, de volta ao Brasil, eu poderia me tornar um pesquisador com preocupações culturais.

Eu sabia que, para os ingleses, esse pressuposto intercultural teria um significado desfavorável. Significaria que gerentes brasileiros são incapazes de compreender a realidade da cooperação interfirma por ainda não terem sido educados de acordo com os modelos do mundo anglo-saxão, usados pelas matrizes das empresas investigadas e também pelas maiores empresas de diversos setores. Eventualmente, o mesmo tipo de interpretação preconceituosa se aplicaria a pesquisadores brasileiros (!).

Descobri que especificidades e resistências culturais não são novidades para os ingleses, ainda que pareçam para os pesquisadores brasileiros. As perspectivas são distintas, por diversas razões sociais e históricas, resultando em problemas específicos ainda não reconhecidos por pesquisadores no Brasil. O primeiro problema é como eles, os ingleses, buscam e definem o chamado "núcleo comum" em administração, o qual seria aplicável em 
diferentes culturas. O segundo problema é que a literatura sobre questões interculturais em administração, tanto em termos de desenvolvimentos conceituais quanto em termos de pesquisas empíricas, é dominada pelos anglosaxões.

The modern student of management should not just study management as unqualified, indiscriminate, amorphous notion. To be sure, management everywhere has a common core, a shared universal managerialism. Organization charts show a hierarchical form with specialist sub-divisions recognizable to all. Everywhere the elite is the elite, a top management level where the main decisions are taken. Everywhere there are calculations of costings and capacities. And so on.

But this common core is surrounded by a diversity of practice on the part of managers, all of whom are stepped in the cultures of societies. From society to society, country to country, nation to nation, the approach to management differs. It differs in the way authority is used, in interpersonal relationships on the job, in communication style, in assertiveness, in speed of action, in bureaucratization, and much more. Even at the center of what seems to be the common core, the formal structures of organizations can vary in terms of the number of layers and number of departmental specialisms.

... the student of management and organization should not panic. When he or she goes into, or return to, a management job, there will be a recognizable common framework of structure and activities whatever the society. (HICKSON, 1997, p.xi)

Em resumo, eu sabia que a abordagem interdisciplinar que eu escolhera (ou tivera que escolher) era equivocada. Por um lado, como um pesquisador profissional, tinha razões muito práticas e plausíveis para manter o equívoco (KINCHELOE; McLAREN, 1994, p.141). Por outro lado, manter o equívoco significava subverter os preceitos do realismo crítico e também suprimir minha identidade como pessoa sociocultural.

Em outra parte da entrevista, J.T. ressaltou, de uma forma ambígua, que a aquisição de uma unidade de fundição pela SPK era fundamental para o entendimento do processo como um todo.

Eu: há uma coisa que não entendo. A unidade de fundição reduziu de forma drástica a estrutura de custos do projeto. Isso me faz entender que o acordo com a MTC [o fornecedor de pinos para a SPK] $e$ com a ALM [a montadora em questão] perdeu um bocado de sua importância. A questão então é: a aquisição da unidade de fundição foi deliberada antes desse projeto, ou não...?

J.T.: sim e não [acompanhado de mais um sorriso irônico].

Eu: bem... no final das contas, a aquisição [da unidade de fundição] aconteceu antes ou depois daquele episódio envolvendo a MTC?

J.T.: aconteceu antes... [sorriso] mas não era direcionada ao projeto que você está investigando... embora [a aquisição] tenha sido fundamental para a viabilização desse projeto. É assim que as coisas acontecem aqui. Eu avisei que seria complicado para você entender essas coisas todas acontecendo ao mesmo tempo. Como é que você vai entender tudo isso? [mais sorrisos]

J.T. me fez perceber que decisões em marketing que parecem seguir o princípio de orientação para o cliente ou para o mercado não são necessariamente motivadas por necessidades de clientes ou do mercado. Esses conceitos, que alicerçam a disciplina e que eu havia assimilado durante o mestrado no Brasil, prescrevem que a empresa deve atender, e preferencialmente se antecipar, às necessidades dos clientes ou do mercado (DAY, 1990; KOHLI; JAWORSKI, 1990; SHAPIRO, 1988). Por isso eu estava impondo com tanta “naturalidade” e convicção, tanto na Inglaterra quanto no Brasil, a lógica de que a aquisição da unidade de fundição representava a antecipação da SPK às necessidades do cliente ou do mercado.

Após investigações adicionais feitas na SPK, descobri que a aquisição da unidade de fundição pela empresa havia alterado significativamente a estrutura de custos do projeto e que as outras empresas da rede focal ficaram 
sabendo apenas de "parte da estória". Mais especificamente, descobri que aquela aquisição aumentara o poder de barganha da SPK em relação tanto à montadora quanto ao fornecedor. Por essa razão, enfrentei dificuldades para ter acesso aos "dados" certos. Também por isso, J.T. sugeria abertamente que eu estava equivocado ao desconsiderar o que ocorria dentro da SPK. Ele tentava dizer que eu não deveria considerar os interesses das diferentes áreas da SPK como "de marketing", mas eu não conseguia ouvi-lo.

O argumento de J.T. era o mais plausível; o problema é que contrariava os conceitos fundamentais da área de marketing. Um obstáculo adicional, naquela pesquisa intercultural, é que os conceitos fundamentais do marketing estavam sendo desafiados por brasileiros.

Ao conseguir não tratar a empresa como uma "caixa preta", descobri que aquela aquisição fazia parte da estratégia corporativa da SPK no contexto da globalização. A estratégia tinha dois objetivos principais:

- reduzir a vulnerabilidade da empresa em relação à ALM; e

- atender ao interesse dos acionistas estrangeiros - que, naquela época, começavam a ampliar sua participação no controle da SPK no Brasil - de aumentar o nível de verticalização da empresa no país, visando aumentar o volume de suas exportações.

Ainda no Brasil, decidi ouvir novamente as fitas das entrevistas com gerentes ingleses e ler as notas da pesquisa de campo. Percebi, então, que havia descartado dados e significados importantes que eram muito parecidos com os obtidos no Brasil. A questão central na comparação entre os resultados é que os gerentes no Brasil, por serem mais "indisciplinados" que os ingleses, diziam mais coisas que eu, como acadêmico disciplinado(r), não estava preparado para "ouvir".

Os relatos dos gerentes ingleses reproduziam bem os princípios da disciplina de marketing. De volta à Inglaterra, após a pesquisa de campo no Brasil, decidi testar aqueles relatos de acordo com os pressupostos do realismo crítico. Com base nas descobertas e reflexões no Brasil, concebi então uma hipótese desafiadora: gerentes disciplinados no Reino Unido segundo teorias e modelos produzidos no mundo anglo-saxão acabam reproduzindo esses mesmos modelos e teorias, especialmente, quando entrevistados por pesquisadores "disciplinados" em marketing. Isso ajudaria a explicar por que o conhecimento produzido no mundo anglo-saxão tampouco se aplicaria ao mundo anglo-saxão.

Essa hipótese foi testada em conversas informais com outros pesquisadores no Reino Unido. Os da área de marketing refutaram sistematicamente esse argumento. Os da área de estudos organizacionais, por sua vez, demonstravam tanto interesse quanto desprezo - esse último sentimento causado pelo fato de eu ser da área de marketing (ou ainda por ser meramente brasileiro).

Logo após a pesquisa de campo no Brasil, relatei a meu supervisor - o mais importante stakeholder (EASTERBY-SMITH; THORPE; LOWE, 1991, p.51) naquele projeto de doutoramento - que as descobertas que tinha feito eram reveladoras e estranhas. Naquela primeira interação, apoiei-me no argumento cultural defendido por pesquisadores no Brasil a partir de meados dos anos 1990. Em outras palavras, usei o argumento de que "estrangeiros" - inclusive ele, meu supervisor - não conseguiriam compreender a realidade brasileira. Até então o supervisor, não obstante ser um dos formuladores do rethinking marketing, também era tido como potencial membro do grupo dos "opressores" - por ser inglês e por fazer parte da academia de marketing. Após ouvir com atenção meus relatos, ele pediu que fizesse o relatório da pesquisa efetuada no Brasil. Quando perguntei o que deveria valorizar e qual tipo de crítica desenvolver ao descrever e analisar os dados, ele sorriu e respondeu de forma inesperada: "não há formato ou agenda ... escreva o que você achar relevante"!. Escrevi então o caso SPK. Ao fazê-lo, respeitei os princípios do realismo crítico e desafiei o argumento cultural defendido por pesquisadores no Brasil acerca do conhecimento vindo do "estrangeiro".

A descrição e a análise do caso SPK mostravam que os gerentes brasileiros descreviam a realidade, enquanto os ingleses enfrentavam obstáculos "acadêmico-culturais" e lingüísticos problemáticos. Quando discuti o documento com meu supervisor, ele concordou com a abordagem resultante e murmurou: "o problema agora vai ser definir quem na Inglaterra será seu avaliador externo...". Percebi que havia ali uma chance de produzir conhe- 
cimento no mundo anglo-saxão, baseado no realismo crítico, que tinha como principal trunfo o conhecimento "indisciplinado" empregado no Brasil. Esse conhecimento fazia sentido e era relevante não somente no Brasil, mas também na Inglaterra.

\section{Considerações finais e implicações futuras}

Este artigo mostrou que muito se aprende quando pesquisadores deixam gerentes falarem por eles mesmos e também como e por que pesquisadores têm dificuldades "para 'ouvir' o que está sendo dito." (BROWNLIE et al, 1999, p.8). Recorrendo a uma abordagem confessional e reflexiva, o artigo também mostrou que a pesquisa acadêmica tem muito a ganhar se deixarmos os pesquisadores falarem por eles mesmos sobre as práticas de pesquisa.

O artigo também mostrou a importância do realismo crítico, tanto para o desenvolvimento do rethinking marketing quanto para os pesquisadores no Brasil preocupados com a questão cultural. $\mathrm{O}$ artigo mostrou que os testes de mecanismos e estruturas hipotéticos feitos pelo pesquisador que segue o realismo crítico não ocorrem "no vácuo". Muitos são os obstáculos dentro e a partir da academia. Aquilo que realistas críticos chamam de descobertas não resulta apenas da realidade "lá fora" ou daquilo que agentes sociais (gerentes ou pesquisadores) têm em suas cabeças, mas principalmente de estruturas, mecanismos e agentes específicos que atuam dentro e a partir da academia.

O artigo também mostrou que realistas críticos devem tratar gerentes como praticantes competentes e valorizar suas "teorias locais" (BARTUNEK; LOUIS, 1996, p.6; CZARNIAWSKA, 1998, p.47), apesar dos desafios e riscos inerentes. Essa abordagem é útil para produzir conhecimento relevante, mas é problemática por desafiar a academia e seu poder de legislar sobre os discursos que ela mesma (re)produz e dissemina.

Discursos produzidos pela academia dos EUA, particularmente na área de marketing, vêm "invadindo" países, constituindo uma cultura acadêmica global. Isso ajuda a explicar reações culturais recentes em diferentes países. Esse fenômeno tem sérias implicações. Uma das consequiências mais sérias, como visto neste artigo, é que cada vez mais os gerentes vão dizer aos pesquisadores o que estes esperam ouvir, visto que os mesmos acadêmicos que ensinam modelos e conceitos a seus alunos, entrevistam "essas mesmas pessoas (agora como profissionais) e lhes perguntam 'como as coisas são'." (ALVESSON; SKÖLDBERG, 2000, p.271). O padrão de "hermenêutica dupla (GIDDENS, 1993) resultante faz com que o conhecimento dominante se afaste cada vez mais da realidade e da relevância (CLEGG; CARTER; KORNBERGER, 2004). Tendo em vista o crescente interesse do mundo anglo-saxão por pesquisa intercultural, esse padrão facilita a construção equivocada do "núcleo comum" em marketing e em outras áreas da administração.

Como ilustrado neste artigo, gerentes menos "disciplinados" pela área de marketing enfrentam menos obstáculos para mobilizar discursos e teorias mais plausíveis para descrever e explicar a realidade. Essa característica ressalta a importância da valorização da cultura local não somente como recurso de resistência, como vem se observando no Brasil e em outros países, mas também como recurso para o desenvolvimento de conhecimento relevante nos âmbitos nacional e internacional. Ademais, esse artigo mostrou como e por que a valorização de conhecimentos e teorias locais pode contribuir para a identificação do "núcleo comum" em marketing, com possível aplicação em outras áreas da administração.

O autor deste artigo argumenta que a abordagem aqui delineada poderá mostrar, pela promoção da pesquisa intercultural na área de marketing, que o conhecimento usado pela gerência no Brasil é mais relevante do que grande parte do conhecimento produzido no "estrangeiro" - inclusive para gerentes e acadêmicos no "estrangeiro". Nesse sentido, o principal foco dessa abordagem é confrontar, com base no realismo crítico, o conhecimento usado por gerentes "indisciplinados' no Brasil e gerentes"disciplinados" no mundo anglo-saxão. Essa abordagem pode ser particularmente interessante para o avanço da proposta do rethinking marketing fora do eixo EUA-Europa. 
Essa abordagem, que nos leva a repensar a "disciplina" de um modo particular, é desafiante em termos políti$\cos$, econômicos e culturais. Além dos obstáculos financeiros e políticos, pesquisadores no Brasil terão que enfrentar dois outros desafios na pesquisa intercultural ainda não problematizados pelos que defendem o debate cultural no Brasil:

- como traduzir significados de uma cultura para outra, e

- como problematizar seus próprios preconceitos, padrões cognitivos e bases referenciais (USUNIER, 1998, p.45).

Finalmente, este artigo ajudou a mostrar que a idéia de que pesquisadores críticos em marketing estão em posição de emancipar praticantes é problemática. Essa ilusória representação acaba contribuindo para impedir que pesquisadores percebam que, antes de tudo, devem promover sua própria emancipação. Reforçando a proposta não-radical do rethinking marketing, este artigo ajudou a mostrar que o discurso da emancipação pode levar o pesquisador a se ver com uma certa autonomia que pouco tem a ver com sua própria realidade dentro da academia. 


\section{Referências}

ACHROL, R. Evolution of the marketing organization; new forms for turbulent environments. Journal of Marketing, v.55, p.77-93, 1991.

ACKROYD, S.; FLEETWOOD, S. (Ed.). Realist perspectives on management and organizations. London: Routledge, 2000.

ALVAREZ, J. The international popularization of entrepreneurial ideas. In: CLEGG, S.; PALMER, G. (Ed.). The politics of management knowledge. London: Sage, 1996.

ALVESSON, M. Organizational symbolism and ideology. Journal of Management Studies, v.28, p.3, p.207-225, 1991.

ALVESSON, M.; WILLMOT, H. Making sense of management: a critical introduction. London: Sage, 1996.

; SKÖLDBERG, K. Reflexive methodology. London: Sage, 2000.

ARCHER, M. Realist social theory: the morphogenetic approach. Cambridge: Cambridge University Press, 1995.

ARGYRIS, C. Increasing leadership effectiveness. New York: John Wiley, 1976.

ARNDT, J. The tyranny of paradigms: the case for paradigmatic pluralism in marketing, in changing the course of marketing: alternative paradigms for widening marketing theory. Research in Marketing, JAI Press, p.1-25, 1985. Supplement 2.

BARTUNEK, J.; LOUIS, M. Insider/outsider team research. London: Sage, 1996.

BAZERMAN, M. Consumer research for consumers. Journal of Consumer Research, v.27, p.499-504, 2000.

BHASKAR, R. A realist theory of science. Brighton: Harvester, 1978.

The possibility of naturalism: a philosophical critique of the contemporary human sciences. $2^{\text {nd }}$ ed. Hemel Hampstead: Harvester Wheatcheaf, 1989.

BRESNEN, M. An organizational perspective on changing buyer-seller relations: a critical review of the evidence. Organization Studies, v.3, n.1, p.121-146, 1996.

BROWN, S. Six sixty-six and all that (or, what the hell is marketing eschatology?). European Journal of Marketing, v.31, n.9/10, p.57-69, 1997.

BROWNLIE, D. Reading the runes: on belief and believing in marketing management research. European Journal of Marketing, v.31, n.11/12, p.744-750, 1997.

et al. The new marketing myopia: critical perspectives on theory and research in marketing - introduction. European Journal of Marketing, v.28, n.3, p.6-12, 1994.

(Ed.) Rethinking marketing: towards critical marketing accountings. London: Sage, 1999.

SAREN, M. The four PS of the marketing concept: prescriptive, polemical, permanent and problematical. European Journal of Marketing, v.26, n.4, p.34-47, 1992.

On the commodification of marketing knowledge: opening themes. Journal of Marketing Management, v.11, n.7, p.619-627, 1995.

Beyond the one-dimensional marketing manager: the discourse of theory, practice and relevance. International Journal of Research in Marketing, v.14, n.2, p.147-162, 1997.

BURRELL, G. Normal science, paradigms, metaphors, discourses and genealogies of analysis. In: CLEGG, S.; HARDY, C.; NORD, W. (Ed.). Handbook of organization studies. London: Sage, 1996.

; MORGAN, G. Sociological paradigms and organizational analysis. London: Heinemann Educational Books, 1979.

CALDAS, M.; WOOD JUNIOR, T. 'For the English to see': the importation of managerial technology in late 20th-century Brazil. Organization, v.4, p.517-534, 1997. 
CAMPBELL, D. Degrees of freedom and the case study. Comparative Political Studies, v.8, p.2, p.178-193, 1975.

CLEGG, S.; CARTER, C.; KORNBERGER, M. A "máquina estratégica": fundamentos epistemológicos e desenvolvimentos em curso. Revista de Administração de Empresas, v.44, n.4, p.21-31, 2004.

; HARDY, C.; NORD, W. Handbook de estudos organizacionais. São Paulo: Atlas, 1999. v.1.

; PALMER, G. (Ed.). The politics of management knowledge. London: Sage, 1996.

COHEN, M.; MARCH, J.; OLSEN, J. A garbage can model of organizational choice. Administrative Science Quarterly, v.17, n.1, p.1-25, 1972.

CZARNIAWSKA, B. A narrative approach to organization studies. London: Sage, 1998.

DAY, G. Estratégia voltada para o mercado. São Paulo: Record, 1990.

DEETZ, S. Describing differences in approaches to organizational science: rethinking Burrell and Morgan and their legacy. Organization Science, v.7, n.2, p.191-207, 1996.

DU GAY, P.; SALAMAN, G. 'The cult[ure] of the customer'. Journal of Management Studies, v.29, n.5, p.615-633, 1992.

EASTERBY-SMITH, M.; THORPE, R.; LOWE, A. Management research: an introduction. London: Sage, 1991.

EASTON, G. Case research as a methodology for industrial networks: a realist apologia. In: XI IMP CONFERENCE, Manchester, 1995. p.368391.

EISENHARDT, K. Making fast strategic decisions in high-velocity environments. Academy of Management Journal, v. 32, n. 3, p. 543-576, 1989.

FARLEY, J.; LEHMANN, D. The important role of meta-analysis in international research in marketing. International Marketing Review, v.18, n.1, p.70-79, 2001.

FLEETWOOD, S.; ACKROYD, S. (Ed.). Critical realism in action in organisations and management studies. London: Routledge, 2004.

FOURNIER, V.; GREY, C. At the critical moment. Conditions and prospects for critical management studies. Human Relations, v.53, n.1, p.7$32,2000$.

FULLER, S. The governance of science. Buckingham: Open University, 2000.

GABRIEL, Y. The state of critique in organizational theory. Human Relations, v.54, n.1, p.23-30, 2001.

GIDDENS, A. The Giddens reader. Houndmills: Macmillan, 1993.

GRINBERG, C.; LUCE, F. Marketing metrics - um novo desafio para a disciplina de marketing. In: ENANPAD, 24., 2000, Florianópolis. Anais.... Florianópolis, 2000.

GUMMESSON, E. Are current research approaches in marketing leading us astray? Marketing Theory, v.1, n.1, p.27-48, 2001.

HAMLIN, C. Realismo critico: um programa de pesquisa para as ciências sociais. Dados - Revista de Ciências Sociais, v.43, n.2, p.373-398, 2000.

HAMMERSLEY, M. The politics of social research. London: Sage, 1995.

HARRÉ, R. Social being: a theory for social psychology. Oxford: Blackwell, 1979.

HASSARD, J. An alternative to paradigm inconmensurability in organizational theory. In: ; PYM, D. (Ed.). The theory and philosophy of organizations. London: Routledge, 1990.

HICKSON, D. (Ed.) Exploring management across the world. Harmondsworth: Middlesex, 1997.

HUNT, S. Truth in marketing theory and research. Journal of Marketing, v.54, p.1-15, 1990.

On rethinking marketing: our discipline, our practice, our methods. European Journal of Marketing, v.28, n.3, p.13-25, 1994. 
IBARRA-COLADO, E. Excellence at large: power, knowledge and organizational forms in Mexican universities. In: CLEGG, S.; PALMER, G. (Ed.). The politics of management knowledge. London: Sage, 1996.

JACKSON, N.; CARTER, P. In defence of paradigm inconmensurability. Organization Studies, v.12, n.1, p.109-128, 1991.

JONES, S. 'Depth Interviews', in WALKER, R. (Ed.). Applied qualitative research. Aldershot: Gower, 1985.

JOHNSON, P.; DUBERLEY, J. Reflexivity on management research. Journal of Management Studies, v.40, n.5, p.1279-1303, 2003.

KAVANAGH, D. Hunt versus Anderson: round 16. European Journal of Marketing, v.28, n.3, p.26-41, 1994.

KINCHELOE, J.; McLAREN, P. Rethinking critical theory and qualitative research, In: DENZIN, N.; LINCOLN, Y. (Ed.). Handbook of qualitative research. London: Sage, 1994.

KNIGHTS, D; MORGAN, G. Organization theory and consumption in a post-modern era. Organization Studies, v.14, n.2, p.211-234, 1993.

KOHLI, A.; JAWORSKI, B. Market orientation: the construct, research propositions and managerial implications. Journal of Marketing, v.54, p.1-18, 1990.

LANGLEY, A. In search of rationality: the purposes behind the use of formal analysis in organizations. Administrative Science Quarterly, v.34, p.598-631, 1989.

MILES, M.; HUBERMAN, A. Qualitative data analysis. London: Sage, 1994.

MORGAN, G. Marketing discourse and practice: towards a critical analysis. In: ALVESSON, M.; WILLMOT, H. (Ed.). Critical management studies. London: Sage, 1992. p.136-158. . Imagens da organização. São Paulo: Atlas, 1997.

Marketing and critique: prospects and problems. In: ALVESSON, M.; WILLMOT, H. (Ed.). Studying management critically. London: Sage, 2003.

MOTTA, F.; ALCADIPANI, R.; BRESLER, R. A valorização do estrangeiro como segregação nas organizações. Revista de Administração Contemporânea, v.5, p.59-79, 2001.

; CALDAS, M. (Ed.). Cultura organizacional e cultura brasileira. São Paulo: Atlas, 1997.

O'DRISCOLL, A.; MURRAY, J. The changing nature of theory and practice in marketing. Journal of Marketing Management, v.14, n.5, p.391-416, 1998.

O'SHAUGHNESSY, J. Temerarious directions for marketing. European Journal of Marketing, v.31, n.9/10, p.677-705, 1997

OUTHWAITE, W. Toward a realist perspective. In: MORGAN, G. (Ed.) Beyond method: strategies for social research. Beverly Hills, CA: Sage, 1983. p.312-330.

PETTIGREW, A. The politics of organizational decision making. London: Tavistock, 1973.

PFEFFER, J. Barriers to the advance of organizational science: paradigm development as a dependent variable. Academy of Management Review, v.18, n. 4, p.599-620, 1993.

RAMOS, A G. The new science of organizations: a reconceptualization of the wealth of nations. Toronto: University of Toronto, 1981.

REED, M. Teorização organizacional: um campo historicamente contestado. In: CLEGG, S.; HARDY, C.; NORD, W. (Ed.). Handbook de estudos organizacionais. São Paulo: Atlas, 1999.

RODRIGUES, S.; CARRIERI, A. A tradição anglo-saxônica nos estudos organizacionais brasileiros. Revista de Administração Contemporânea, v.5, p.81-102, 2001.

SCHÖN, D. The reflective practitioner. New York: Basic Books, 1983.

SHAPIRO, B. What the hell is 'market-oriented'? Harvard Business Review, v. 66, n. 6, p.119-125, 1988. 
STABLEIN, R. Dados em estudos organizacionais. In: CLEGG, S.; HARDY, C.; NORD, W. (Ed.). Handbook de estudos organizacionais, São Paulo: Atlas, 2001. v.2.

USUNIER, J.-C. International \& cross-cultural management research. London: Sage, 1998.

VAN MAANEN, J. The fact of fiction in organizational ethnography. Administrative Science Quarterly, v.24, p.539-550, 1979.

Commentary - on the matter of voice. Journal of Management Inquiry, v.5, n.4, p.375-381, 1996.

VIEIRA, F. Narciso sem espelho: a publicação brasileira de marketing. Revista de Administração de Empresas, v.43, n.1, p.81-90, 2003.

VIEIRA, M.; CALDAS, M. Teoria crítica e pós-modernismo: principais alternativas à hegemonia funcionalista em gestão. Revista de Administração de Empresas, v.46, n.1, p.59-70, 2006.

WEICK, K. The social psychology of organizing. New York: Mc-Graw-Hill, 1969.

Sensemaking in organizations. London: Sage, 1995.

WENSLEY, R. A critical review of research in marketing. British Journal of Management, v.6, p.s63-s82, 1995. Special Issue.

The MSI priorities: a critical view on researching firm performance, customer experience and marketing. Journal of Marketing Management, v.16, p.11-27, 2001.

YIN, R. Case study research - design and methods. London, Sage, 1994. 